\title{
The parameter analysis of creep prediction mode
}

\author{
Kongliang Chen ${ }^{1, a^{*}}$ Ronghui Wang ${ }^{2, b}$ Jianhong Liao ${ }^{3, c}$ \\ ${ }^{1}$ School of Civil Engineering and architecture, WuYi University ,Jiangmen, China. \\ ${ }^{2}$ School of Civil Engineering and Transportation, South China University of Technology,Guangzhou, \\ China \\ ${ }^{3}$ Transportation Planning Survey and Design Institute of Hunan Province, China \\ ackongliang@163.com, brhwang@scut.edu.cn, ‘jianhongliao@126.com
}

Keywords: creep, model, parameters

Abstract: According to current creep prediction mode, four kinds of concrete creep prediction model(CEB-FIP 90, ACI 209 (92), RILEM B3 and GL2000) are selected to analyze in this paper. Based on the same conditions for creep factors, some important parameters of four creep modes are analyzed and regular patterns of creep are summarized.

\section{Introduction}

How to study concrete creep mechanism ${ }^{[1]}$ and to improve the prediction accuracy of concrete creep effect are contemporary bridge experts constantly striving to the subject. Based on a number of creep test data acquisition and computer database establishment, the development of statistical calculation procedures and the physical processes of creep gradually are recognized ${ }^{[2-3]}$ in order to forecast creep. Concrete creep factors are concluding water-cement ratio, strength, cement type, component size and the shape of the cross-sectional component, and the environmental factors are concluding such as temperature, humidity, curing conditions, loading age and dry age ${ }^{[4-6]}$, and concrete creep factors can be divided into internal and external factors, the internal composition of material factors are including the amount and proportion of concrete, concrete component size and make conservation, and external factors include concrete under load, load characteristics and work environment.

\section{Analysis parameters effect of creep}

Most of existing creep mode are used as the multiplication of creep coefficient and develop function of creep time to express. Nominal concrete creep are related to concrete cube compressive strength, theoretical thickness, relative humidity and other factors, and the development of concrete creep are related to the theoretical thickness and component factors over time. Therefore, this section analyzes the impact of relative humidity, concrete strength, theoretical thickness and load duration on nominal creep coefficient, and creep coefficient of the different modes is with the development law over time.

\section{Influence of relative humidity on nominal creep coefficient}

The relationship between the relative humidity and the nominal creep coefficient is shown in fig.1, of which the nominal creep coefficient is reduced with the relative humidity increase. The nominal creep coefficient of CEB-FIP 90 model and ACI 209 (92) mode are linear relationship, while the nominal creep coefficient of RILEM B3 model and GL2000 are the parabola relationship, 
where the creep coefficient curves of the RILEM B3 model GL2000 are respectively downward opening parabola and upward opening parabola. Nominal coefficient creep of CEB-FIP 90 model is the maximum, and other creep coefficient is between 0 and 2 .

\section{Influence of theoretical thickness on nominal creep coefficient}

The influence of theoretical thickness on the nominal creep coefficient is shown in Fig.2, and the theoretical thickness variations of RILEM B3 model and GL2000 mode have no effect on the nominal creep coefficient. The figure shows that the greater the thickness of the theory, nominal creep coefficient is smaller. The nominal creep coefficient of ACI 209 (92) model is the minimum creep coefficient, and nominal creep coefficient of ACI 209 (92) is between 1 and 2, and the nominal creep coefficient of CEB-FIP 90 is between 1 and 5.

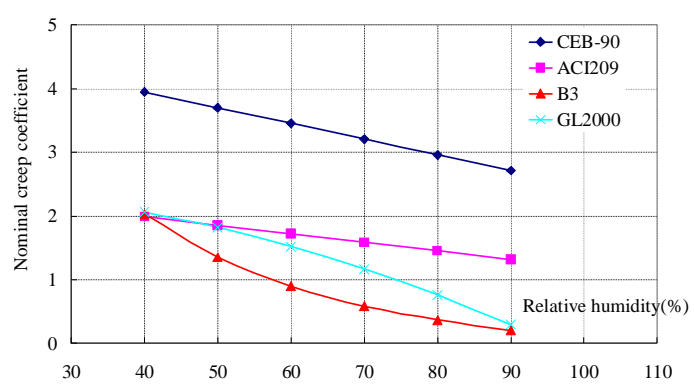

Fig.1 The curves of nominal creep coefficient on relative humidity

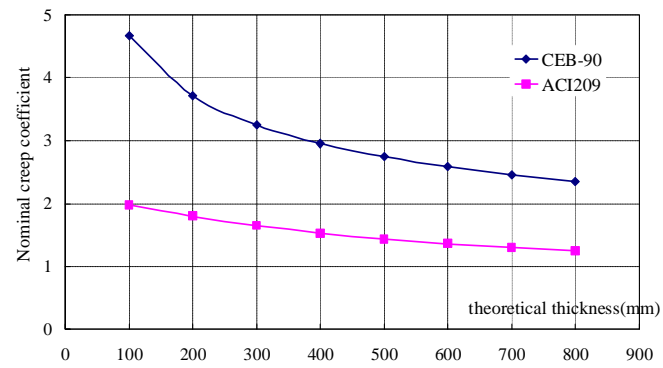

Fig.2 The curves of nominal creep coefficient on theoretical thickness

\section{Influence of concrete strength on nominal creep coefficient}

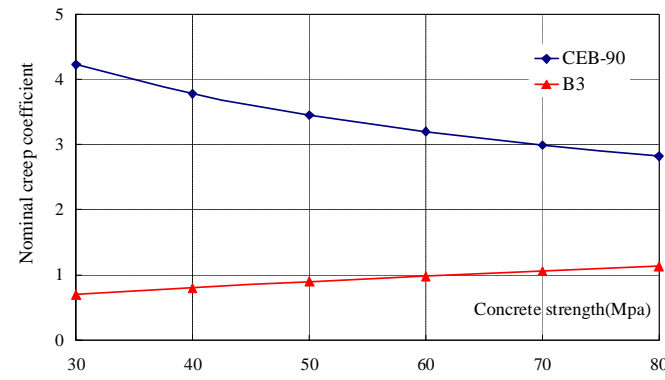

Fig.3 The curves of nominal creep coefficient on concrete strength

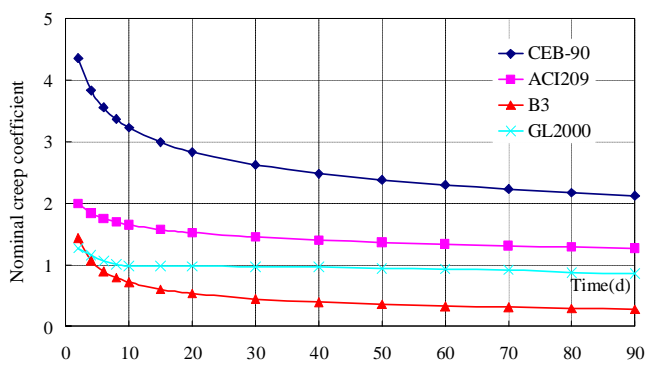

Fig.4 The curves of nominal creep coefficient on loading age

The influence of concrete strength on the nominal creep coefficient is shown in Fig.3, CEB-FIP 90 model and RILEM B3 model which is considered the influence of concrete strength is on the creep coefficient, and the relationship shown in Fig. 3. The figure shows that nominal creep coefficient of CEB-FIP 90 model decreases with the increases of concrete strength, and the nominal creep coefficient of RILEM B3 model decreases with the increase of concrete strength, but the magnitude of the increase can be ignored

\section{Influence of loading age on nominal creep coefficient}

The influence of loading age on the nominal load creep coefficient is shown in Fig.4. Creep coefficient decreases with age. The nominal creep coefficient of RILEM B3 is the minimum and the coefficient of CEB-FIP 90 model is the maximum. When the loading age is less than 30 days, it will be a greater impact on the creep. 


\section{The law development of creep coefficient curves}

Four modes of creep coefficient curve with the development of time are shown in Fig.5. The figure shows that the creep coefficient is basically the same with the development of the law of the time, which are the early development of rapid and post-moderated. Creep coefficient of GL2000 model is the maximum, and the coefficient of RILEM B3 model is the minimum. According to the CEB-FIP 90, ACI 209 (92) and RILEM B3 model, The creep in first year is accounted for about more than 80 percent in the first three decades of creep; the creep of GL2000 model in the first year is accounted for 70 percent in three decades.

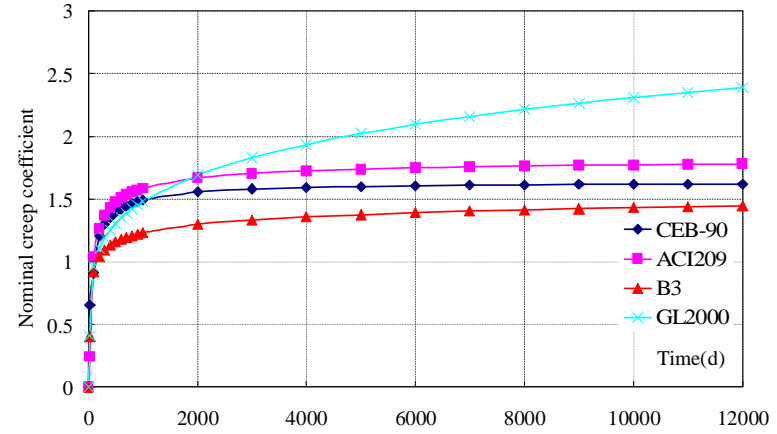

Fig.5 The development of the creep coefficient over time

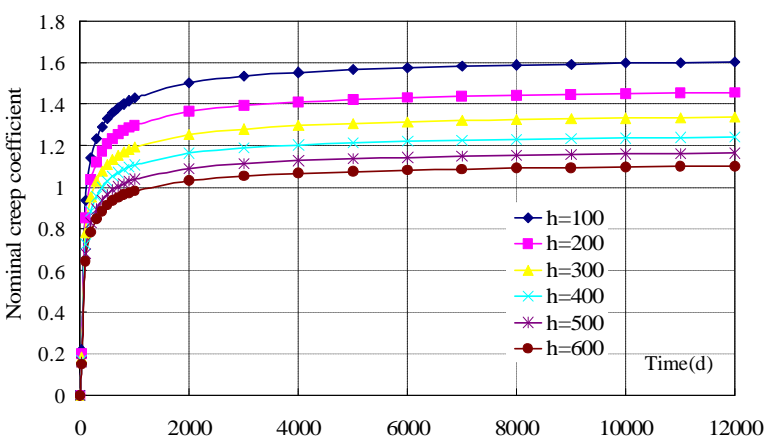

Fig. 7 the development of the creep coefficient over time with theoretical thickness variation (RILEM B3 mode)

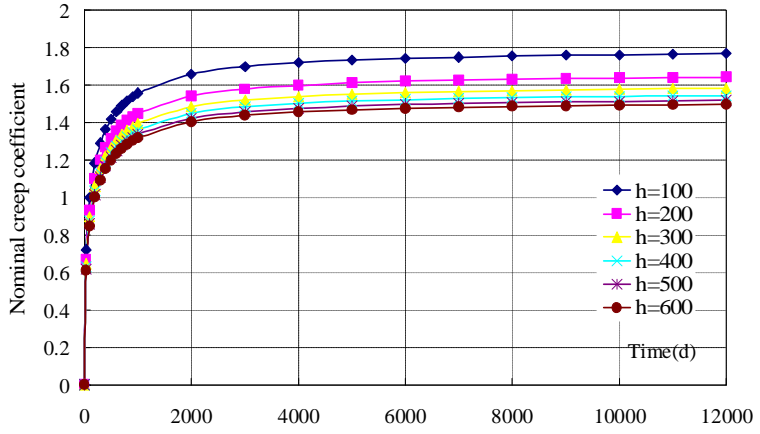

Fig. 6 the development of the creep coefficient over time with theoretical thickness variation ( CEB-FIP 90 mode )

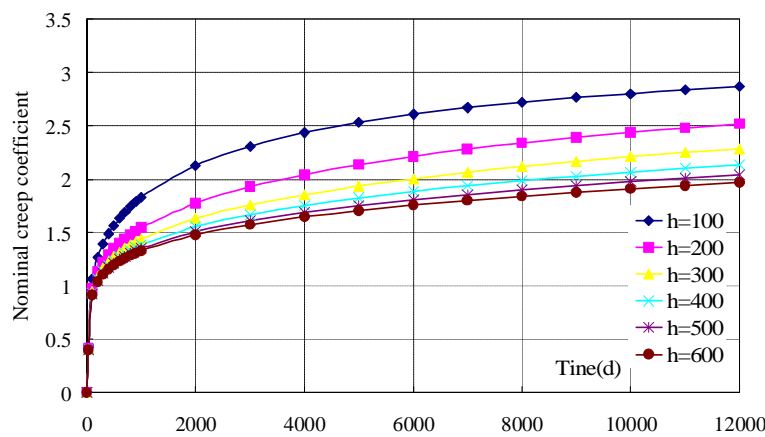

Fig.8 the development of the creep coefficient over time with theoretical thickness variation ( GL2000 mode )

\section{The development law of relative humidity and theoretical thickness curves}

It can be seen from the Figs 6 to 8, several models of creep coefficient are similar development curve over time in the theoretical thickness varying conditions, and the creep coefficient of ACI 209 (92) mode does not consider the thickness, but other creep coefficient decreases with increasing theoretical thicknessl, and two models are the first 2000 completed the first three days. 


\section{Conclusion}

The mechanism and influencing factors of the concrete creep are discussed in this paper, and the following conclusions can be drawn in this paper.

Based on the same parameters of four prediction modes, the creep coefficient of GL2000 models is the maximum, and nominal theoretical thickness is only influential to CEB-FIP 90 model and ACI 209 (92) mode creep coefficient, and concrete strength is greater impact on nominal coefficient of CEB-FIP 90 model. Loading age has influence on behalf of the four modes of creep coefficient; when the loading age is not more than 30 days, and the loading age is greater impact on creep coefficient, but with the increase of loading age, the impact on the creep factor is gradually smaller.

\section{Acknowledgements}

The project surported (No. 200820) from Department of communication of Hunan Province, and surported (No.20140080089566) from Department of communication of Jiangmen.

\section{References}

[1] Hatt W K. Notes on effect of time element in loading reinforced concrete beams. Proc. ASTM. Commun.11(1911) P. 531-555.

[2] Bazant Z. P. and BAWEJA S. Justification and refinements of model B3 for concrete creep and shrinkage- Statistic and sensitity. Materials and Structures, Vol.28 (1995) P. 415-430.

[3] Bazant Z. P. and Baweja.. Creep`and shrinkage predication model for analysis and design of concrete structures-model B3. Materials and Sturctures. Vol.28 (1995) P. 357-365.

[4] Bazant Z. P.. Viscoelasticity of a solidifying porous material-concrete. Journal of Engineering Machanics, ASCE, Vol.103 (1977) P.1049-1067.

[5] Bazant Z. P. . Thermodynamics of solidifying or melting viscoelastic material. Journal of Engineering Mechanics, ASCE, Vol. 105(1979) P. 933-852.

[6] Bazant Z. P. . Solidification theory for concrete Creep I: Formulation[J]. Journal of Engineering Mechanics, ASCE, Vol.115 (1988) P. 1691-1703. 